\title{
Müşteri Sözlü Saldırganlığının Çalışanların İşten Ayrılma Niyeti Üzerine Etkisi: Duygusal Tükenmenin Aracılık Rolü
}

\section{The Effect of Verbal Customer Aggression on Employee Turnover Intention: The Mediating Role of Emotional Exhaustion}

\author{
Salih Dursun' ${ }^{\circledR}$, Oğuz Başol' 1 (1)
}

\section{Öz}

Hizmet sektörü günümüzün hızla büyüyen sektörlerinden biridir ve bu sektörde istihdam edilenlerin sayısı ve oranı her geçen yıl artmaktadır. Ancak, çalışanlar ile müşteriler arasındaki güç dengesizliği zaman zaman çalışanlar ve müşteriler arasında negatif etkileşim olmasına neden olmaktadır. Bu bağlamda hizmet işlerinin "karanlık yüzü" olarak görülen müşteri saldırganlığı olgusu, günümüz iş hayatının önemli sorun alanlarından biridir. Mevcut araştırma, müşteri sözlü saldırganlığının çalışanların işten ayrılma niyeti üzerine etkisinde duygusal tükenmenin aracılık rolünü belirlemeyi amaçlamaktadır. 351 satış ve müşteri temsilcisinin katlımıyla gerçekleştirilen araştırma sonuçları, müşteri sözlü saldırganlığının duygusal tükenmeyi ve işten ayrılma niyetini pozitif yönde etkilediğini göstermektedir. Ayrıca elde edilen sonuçlar, duygusal tükenmenin, müşteri sözlü saldırganlığı ve işten ayrılma niyeti ilişkisinin tam aracısı olduğunu göstermektedir. Bulgular, işletme yönetimlerinin müşteriden kaynaklanan saldırgan davranışları önleyici politikalar üretmesinin, çalışanların duygusal tükenmesinin ve işten ayrılma niyetinin azaltılması açısından oldukça önemli olduğunu göstermektedir.

\section{Anahtar Kelimeler}

Müşteri saldırganlığı, Sözlü saldırganlık, Duygusal tükenme, İşten ayrılma niyeti, Aracılık

1 Sorumlu Yazar: Salih Dursun (Doç. Dr.), Karadeniz Teknik Üniversitesi, İktisadi ve İdari Bilimler Fakültesi, Çalışma Ekonomisi ve Endüstri İlişkileri Bölümü, Trabzon, Türkiye. E-posta: sdursun@ktu.edu.tr ORCID: 0000-0002-8597-3340

2 Oğuz Başol (Doç. Dr.), Kırklareli Üniversitesi, İktisadi ve İdari Bilimler Fakültesi, Çalışma Ekonomisi ve Endüstri İlişkileri Bölümü, Kırklareli, Türkiye. E-posta: oguzbasol@klu.edu.tr ORCID: 0000-0002-7523-4544

Atıf: Dursun, S. ve Basol, O. (2020). Müşteri sözlü saldırganlığının çalışanların işten ayrılma niyeti üzerine etkisi: Duygusal tükenmenin aracılık rolü. Sosyal Siyaset Konferansları Dergisi,78: 147-169. https://doi.org/10.26650/jspc.2019.78.0042 


\begin{abstract}
The service sector is one of the rapidly growing sectors of today, and the number and rate of people employed in this sector are increasing every year. But, the power imbalance between employees and customers occasionally causes negative interactions between employees and customers. In this respect, the phenomenon of customer aggression, seen as the "dark side" of service work, is one of the important problem areas of today's business life. This research aims to determine the mediating role of emotional exhaustion in the effect of verbal customer aggression on employees' turnover intention. The results of the research, conducted with the participation of 351 sales and customer representatives, show that customer verbal aggression positively affects the emotional exhaustion and turnover intention. Also, the results show that emotional exhaustion fully mediates the relationship between verbal customer aggression and turnover intention. The obtained results show that it is very important for organization administrations to produce policies to prevent customer aggressive behaviors in terms of decreasing the emotional exhaustion and turnover intention of employees.
\end{abstract}

\title{
Keywords
}

Customer aggression, Verbal aggression, Emotional exhaustion, Turnover intention, Mediator 


\section{Extended Summary}

As a result of the extension of the service sector, a consumer-centered economic system emerged (Rafaeli et al., 2012, p. 931). The fact that customer satisfaction has become so important, and today's customer-oriented approach leads the companies running in this area to adopt the philosophy of "the customer is always right", hence, this results in an unequal power mechanism between employees and customers (Grandey, Dickter \& Sin, 2004, p. 3; Choi, Kim, Lee \& Lee, 2014, p. 273). As a reflection of this, employees may be subjected to treatment such as verbal harassment, unfair demands and disrespectful behaviors from customers (Wang et al., 2013, p. 989). One of the concepts used in the literature to express negative behaviors caused by the customer is verbal customer aggression. The concept of verbal customer aggression expresses customer behaviors such as swearing, shouting, threatening, humiliation and mocking (Grandey, Kern \& Frone, 2007, p. 68; Yeh, 2015, p. 1; Li \& Zhou, 2013, p. 893).

Studies show that customer-related aggressive behavior is quite common (Grandey, Dickter \& Sin, 2004; Hughes \& Tadic, 1998; Harrris \& Reynolds, 2003; Akgeyik \& Delen, 2009; Kavi \& Ceylan, 2016). The increase in the frequency of customer aggression also increases the burnout levels of employees (Grandey et al., 2004, p. 402). Also, social interactions based on unequal relationships between service workers and customers trigger greater resource loss and lead to emotional exhaustion (Kim, Paek, Choi \& Lee, 2012, p. 508; Gong, Sun \& Zhang, 2018; Demerdash \& Said, 2018; Kind, Eckert, Steinlin, Ferget \& Schmid, 2008). Studies show that customerrelated negative behavior and emotional exhaustion may be the sources of the turnover intention of employees' (Walsh, 2011, p. 68; Liu et al., 2018; Gong et al., 2018; Bamfo, Dogbe \& Mingle, 2018; Onay ve Kılc1, 2011, p. 372; Yıldırım, Erul \& Kelebek, 2014, p. 40; Yıldız \& Çolak, 2018, p. 625; Interest, 2019, p. 34; Adams, Hollingsworth \& Osman, 2019, p. 455; Kim, 2019, p. 21). Also, there are some studies investigate the mediating effect of burnout in the effect of customer-related aggressive behavior on turnover intention (Han, Bonn \& Cho, 2016; Karatepe, Yorganci \& Haktanır, 2009b). 


\section{Method}

The sample of the study consists of 351 employees working as sales and customer representatives in the service sector in Trabzon, Turkey. The survey form consists of four parts. The first part aims to determine the demographic characteristics of the participants. The second part aims to detect the verbal customer aggression that employees are exposed to. The scale used in this section is the 5 -item verbal customer aggression scale, developed by Dormann and Zapf (2004), and the validity-reliability study is carried out by the authors. The third section aims to determine the level of emotional exhaustion experienced by customer representatives. The scale used in this section is the 9-item emotional exhaustion scale, developed by Maslach and Jackson (1981), and the validity-reliability study was performed by Üngüren, Doğan, Özmen and Tekin (2010). The last section aims to determine the turnover intention of the customer representatives. The 3-item turnover intention scale, developed by Cammann, Fichman, Jenkins and Klesh (1979) and the validityreliability studies conducted by Gül, Gökçe and Gökçe (2004) were used.

\section{Results}

According to the results, $50.4 \%$ of the participants are women, $48.4 \%$ are married and 39\% have a bachelor-degree level. The ages of the participants ranged from 18 to 50, with an average age of $29( \pm 5.96)$, and their experience ranged from 1 to 27 years, with an average of 6 years $( \pm 4.97)$. Preacher and Hayes (2004: 721-722) macro was used to test the hypotheses in SPSS. For estimation, the 5000 bootstrapping and a bias-corrected percentile method were used to determine the $95 \%$ confidence interval. Accordingly, verbal customer aggression has a positive effect on emotional exhaustion ( $\beta$ : 0.40; t: 6.91), verbal customer aggression positively affects employees' turnover intention $(\beta: 0.51 ; \mathrm{t}: 4,97)$, emotional exhaustion positively affects the turnover intention ( $\beta$ : $1.42 ; \mathrm{t}: 25.21)$ and finally, emotional exhaustion has a fully mediating role in the effect of customer verbal aggression on turnover intention ( $\beta$ ': $-0,60$; t: -0.92 - Sobel Z: 6.66789; p: 0.00).

\section{Discussion}

Many studies in the literature show that one of the important problems caused by verbal customer aggression is emotional exhaustion (Grandey et 
al., 2007; Ben-Zur and Yagil, 2005; Karatepe et al., 2010b; Dursun \& Aytaç, 2014; Sommovigo, Setti \& Argentero, 2019). Also, the literature shows that customer aggression has a significant impact on the turnover intention of employees' (Karatepe et al., 2009a; Gong et al., 2018; Bamfo et al., 2018), emotional exhaustion has a positive effect on the turnover intention and lastly, emotional exhaustion has a fully mediating role in the effect of verbal customer aggression on turnover intention (Onay \& K1lc1, 2011; Y1ldırım et al., 2014; Yıldız \& Çolak, 2018; Faiz, 2019; Adams et al., 2019; Kim, 2019; Grandey et al., 2004; Karatepe et al., 2009). 


\section{Müşteri Sözlü Saldırganlığının Çalışanların İşten Ayrılma Niyeti Üzerine Etkisi: Duygusal Tükenmenin Aracılık Rolü}

Hizmet sektörü günümüzün hızla büyüyen sektörlerinden biridir ve bu sektörde istihdam edilenlerin oranı her geçen yıl artış göstermektedir. Hizmet sektörünün yaygınlaşması sonucunda önemli hale gelen tüketici merkezli ekonomide, müşteri memnuniyetinin kurumsal başarı üzerindeki etkisini göz ard1 etmek imkansızdır (Rafaeli vd., 2012, s. 931). Müşteri memnuniyetinin bu denli önemli hale gelmesi ve günümüzün müşteri odaklı anlayışı, bu alanda faaliyet gösteren işletmelerin "müşteri kraldır" veya "müşteri her zaman haklıdır" felsefesini benimsemelerine yol açmakta ve bu durum çalışanlar ile müşteriler arasında eşit olmayan bir güç mekanizmasıyla sonuçlanmaktadır (Grandey, Dickter ve Sin, 2004, s. 3; Choi, Kim, Lee ve Lee, 2014, s. 273). Günümüzde bir çok şirketin çalışanlara yönelik, müşterilerinin saldırgan davranışlarında bile "gülümsemeyle müşterilere hizmet etmelerini" şart koşan çok sıkı politika ve düzenlemeleri bulunmaktadır (Choi vd., 2014, s. 273; Han, Bonn ve Cho, 2016, s. 97).

Hizmet sektörü doğası gereği, hizmet sunulan kişilerle çalışanlar arasında yoğun etkileşimi gerektirmektedir. Diğer taraftan çalışanlar ile müşteriler arasındaki güç dengesizliğinin bir sonucu olarak çalışanlar zaman zaman müşteriden kaynaklı sözlü taciz, haksız talepler ve saygısız davranışlar gibi kötü muamelelere maruz kalabilmektedir (Wang vd., 2013, s. 989). Literatürde müşteriden kaynaklanan olumsuz davranışları ifade etmek için; taciz edici müşteri davranışları (Bamfo, Dogbe ve Mingle, 2018), müşteri sapkın davranışları (Reynolds ve Harris, 2006), kızgın müşteriler (Dallimore, Saprks veButcher, 2007), müşterilerle ilgili sosyal stresörler (Dormann veZapf, 2004), dostça olmayan müşteri davranışları (Walsh, 2011), müşteri nezaketsizliği (Han, Bonn ve Cho, 2016), anormal müşteri davranışı (Fullerton ve Punj, 1993), fonksiyonel olmayan müşteri davranışları (Harris ve Reynolds, 2003), müşteri adaletsizliği (Rupp, McCance, Spencer ve Sonntag, 2008; Yürür, Gümüş ve Hamarat, 2011) ve müşteri öfkesi (Patterson, McColl-Kennedy, Smith ve Lu, 2009) gibi farklı kavramların kullanıldığı görülmektedir.

Müşteri saldırganlığı kavramı da müşteriden kaynaklanan olumsuz davranışları ifade etmek için sıklıkla kullanılan kavramlardan biridir (Grandey, Kern ve Frone, 2007; Bedi ve Schat, 2007). Günümüzde genişleyen hizmet sektörü, müşteri odaklı yönetim anlayışı, duygusal emek beklentisi ve 
kurumsal faktörler (kapalı ve otokratik yönetim anlayışı, aşırı iş yükü, kötü fiziksel çalışma koşulları vb.) müşteri saldırganlığını yaygınlaştırmaktadır (Akgeyik ve Delen, 2013, s. 22-28). Müşteri saldırganlı̆̆ bir yandan çalışanlar için iş tatmini, örgütsel bağl1lık ve örgütsel vatandaşlık davranışı gibi olumlu tutumların düşmesine; duygusal tükenme, işe devamsızlık ve işten ayrılma niyeti gibi olumsuz tutumların artmasına neden olurken; diğer yandan örgütler için verimlilik ve üretkenlik kaybı gibi olumsuz sonuçların artmasina sebebiyet verebilmektedir.

Müşteri saldırganlığının önemli yansımalarından biri, çalışanların duygusal tükenme düzeylerini arttırmasıdır. Bu bağlamda araştırmalar, müşteri kaynaklı olumsuz davranışlara maruz kalan çalışanların duygusal tükenme düzeylerinin artabileceğini göstermektedir (Kind, Eckert, Steinlin, Ferget ve Schmid 2008; Kim, Paek, Choi ve Lee, 2012; Gong vd., 2018; Demerdash ve Said, 2018). Müşterilerden kaynaklı adaletsiz davranışların bir diğer yansıması ise işten ayrılma niyeti üzerinedir. Araştırmalar, müşteri nezaketsizliği ile karşılaşan çalışanların işten ayrılma niyetinin yükselebileceğini göstermektedir (Walsh, 2011, Liu vd., 2018; Gong vd., 2018; Bamfo vd., 2018). Bu bulgulardan hareketle, müşterilerin adaletsiz davranışlarının örgütlerin en değerli ve yetenekli kaynağı olan insan faktörünü tehdit ettiğini söylemek yerinde olacaktır. Nitekim mevcut araştırma da müşteri kaynaklı sözlü saldırganlık davranışı ile işten ayrılma niyeti arasındaki ilişkide duygusal tükenmenin aracılık rolünü incelemeyi amaçlamaktadır.

\section{Kavramsal Çerçeve ve Hipotezler}

\section{Müşteri Sözlü Saldırganlığı}

İşyeri saldırganlığı ile ilgili araştırmalar genellikle saldırgan davranışın kaynağ1 veya hedefi olarak örgüt içindeki kişiler üzerine yoğunlaşmakla beraber bazen örgütün hizmet sunduğu kişiler yani müşteriler de olabilmektedir (Grandey vd., 2004, s. 397-398). Hizmet işlerinin "karanlık yüzü” olarak görülen müşteri saldırganlığı olgusu (Goussinsky, 2011, s. 171) günümüz iş hayatının önemli örgütsel sorun alanlarından biri olarak kabul edilmektedir (Akgeyik ve Delen, 2013, s. 18).

Müşteriden kaynaklanan saldırgan davranışlar farklı düzeylerde kendini göstermektedir. Baron (1993), müşteri tarafından hizmet çalışanlarına yönelik 
birbiriyle bağlantısı olan üç düzeyde saldırganlık olduğunu ifade etmektedir. Buna göre birinci düzey, işbirliği yapmama, söylentileri yayma ve müşteri tarafından saldırgan dil kullanma davranışlarını içermektedir. İkinci düzey, şiddetli tartışmalar ve sözlü tehditleri kapsamaktadır. Son olarak üçüncü düzey ise aşırı öfke, fiziksel kavgalar ve silah kullanımı davranışlarını içermektedir. Müssteri saldırganlığının ilk iki düzeyi esas olarak sözel saldırganlık türleri ile bağlantılı olan davranışlar olarak değerlendirilmektedir (Getnet ve Malik, 2012, s. 1).

Müşteri sözlü saldırganlığı kavramı, çalışana yönelik küfür etmek, bağırmak, tehdit etmek, aşağılamak ve alay etmek gibi müşteri davranışlarını ifade etmektedir (Grandey vd., 2007, s. 68; Yeh, 2015, s. 1). Bu tür sözlü saldırganlık davranışları geniş bir yelpazede kendini göstermekte ve tehdit, bağırma, sözlü cinsel taciz, hakaret, söylenti çıkarma, fikirleri aşağılama, geçerli bir sebep olmaksızın şikayette bulunma, çalışanla tartışma veya aşırı taleplerde bulunma gibi saldırgan davranışları içermektedir (Li ve Zhou, 2013, s. 893). Ayrıca bu tür saldırgan davranışlar yalnızca müşteri ve çalışanlar arasındaki yüz yüze etkileşimi değil, telefon veya e-posta yoluyla etkileşimleri de kapsamaktadır (Yeh, 2015, s. 878). Sonuç olarak müşteri sözlü saldırganlığı, saygısız, sabırsız ve kaba sözlü ifadeler yoluyla rahatsızlığa neden olan ve çalışanlara zarar veren durumlar olarak tanımlanmaktadır (Li ve Zhou, 2013, s. 893).

Araştırmalar, müşteriden kaynaklı saldırgan davranışların oldukça yaygın olduğunu göstermektedir. Grandey vd. (2004) tarafından çağrı merkezi çalışanları üzerinde yapılan bir araştırma, çalışanların günde ortalama 10 kez müşteri saldırganlığına maruz kaldığını göstermektedir. Benzer şekilde Hughes ve Tadic (1998) tarafından gerçekleştirilen çalışma da perakende hizmetlerde çalışan kadınların \%60'ının müşteriden kaynaklanan cinsel taciz davranışlarına maruz kaldıklarını göstermektedir. Harrris ve Reynolds (2003) ise çalışmasında otel, restoran ve bar çalışanlarından oluşan katılımcıların \%82'sinin son bir yıl içinde müşteri saldırganlığına maruz kaldığını veya tanıklık ettiğini dile getirmektedir.

Türkiye'de ise müşteri saldırganlığı ile ilgili kısıtlı sayıda çalışmanın yapıldığı görülmektedir. Akgeyik ve Delen (2009) tarafindan market ve çağrı merkezlerinde istihdam edilen ön ofis çalışanları üzerinde yapılan araştırmada katılımcıların \%78,1'inin müşteri saldırganlığına maruz kaldığ 1 tespit 
edilmiştir. Araştırmada en sık maruz kalınan saldırganlık biçimleri, \%68,6 ile azarlanma, \%48,2 ile aşağılayıcı ifadeler ile karşılaşma ve \%44,5 ile aşırı şekilde eleştirilme olarak görülmektedir. Kavi ve Ceylan (2016) tarafından kargo çalışanları üzerinde yapılan bir başka araştırma da katılımcıların \%94,4’ünün müşteri saldırganlığına maruz kaldıkları tespit edilmiştir. Maruz kalınan saldırganlık türü ise ağırlıklı olarak hakaret, küfür ve aşağılayıcı ifadeler $(\% 68,5)$ gibi sözlü saldırganlık durumlarıdır.

\section{Müşteri Sözlü Saldırganlığı ve Duygusal Tükenme}

Araştırmalar hizmet çalışanları arasında tükenmişliğin önemli bir sorun olduğunu göstermektedir (Singh, Goolsby ve Rhoades, 1994; Lizano, 2015, Gong, Sun ve Zhang, 2018). Maslach ve Jackson (1981, s. 99) tükenmişliği artan duygusal tükenme, diğer insanlara karşı duyarsızlaşma ve kişisel başarıda düşme hissi olarak görülen bir sendrom olarak tanımlamıştır. Tükenmişlik sendromunun önemli bir yönü ise duygusal yorgunluk hissinin artmasıdır (Maslach ve Jackson, 1981, s. 99). Duygusal tükenme olarak ifade edilen bu durum, aşırı psikolojik talepler nedeniyle ortaya çıkan duygusal bitkinlik ve enerjinin tükenmesi duygularını içermektedir (Boles, Dean, Ricks, Short ve Wang, 2000, s. 13). Hizmet çalışanları özellikle duygusal tükenmeye karş1 hassastır, çünkü bu stres faktörleriyle karşı karşıya kaldıklarında, çalışanların iş taleplerini karşılamak ve duygularını düzenlemek için ekstra çaba göstermeleri gerekmektedir (Li ve Zhou, 2013, s. 894). Nitekim araştırmalar müşteri sözlü saldırganlığının duygusal uyumsuzluğa yol açtığını göstermektedir (Yeh, 2015; Molino vd., 2016).

Özellikle müşteri saldırganlığının sıklığının artması, çalışanlarda stres düzeylerinin artması nedeniyle ortaya çıkan tükenmişlik durumunu da arttırmaktadır (Grandey vd., 2004, s. 402). Ayrıca hizmet çalışanları ve müşteriler arasındaki eşitsiz ilişkiye dayanan sosyal etkileşimler daha fazla kaynak kaybını tetiklemekte ve duygusal tükenmeye yol açmaktadır (Kim, Paek, Choi ve Lee, 2012, s. 508). Bu konuda yapılan araştırmalar da müşteri saldırganlığının çalışan tükenmişliğini etkilediğini göstermektedir. Gong vd. (2018) satış çalışanları üzerinde yaptığı çalışmasında, müşteri sözlü saldırganlığının çalışanların tükenmişlik düzeyinin artmasına neden olduğunu tespit etmiştir. Demerdash ve Said (2018) müşteri sözlü saldırganlığ1 ile tükenmişlik arasında pozitif bir ilişki olduğu sonucuna ulaşmıştır. Kind, 
Eckert, Steinlin, Ferget ve Schmid (2008) ise profesyonel bakıcıların maruz kaldıkları sözlü saldırganlığın tükenmişliği pozitif etkilediğini tespit etmiştir.

Ayrıca araştırmalar, müşteri sözlü saldırganlığının özellikle duygusal tükenme üzerinde önemli bir etkiye sahip olduğunu göstermektedir. Grandey vd. (2007) tarafından yapılan çalışmada müşterinin sözlü tacizinin duygusal tükenmeye yol açtığı görülmektedir. Grandey vd. (2004), Ben-Zur ve Yagil (2005), Karatepe, Yorganci ve Haktanır (2009a), Dursun ve Aytaç (2014), Sommovigo, Setti ve Argentero (2019) tarafindan gerçekleştirilen çalışmalarda da müşteri sözlü saldırganlığı ile duygusal tükenme arasında pozitif bir ilişki olduğu tespit edilmiştir. Bu bilgiler 1şığında araştırmanın birinci hipotezi şu şekilde belirlenmiştir:

H1:Müşteri sözlü saldırganlığı duygusal tükenme üzerinde pozitif etkiye sahiptir.

\section{Müşteri Sözlü Saldırganlığı ve İşten Ayrılma Niyeti}

İşten ayrılma niyeti kavramı, "çalışanın örgütten ayrılmak için bilinçli ve planlı istekliliğii” (Tett ve Meyer, 1993, s. 262) veya “çalışanın çalışmış olduğu örgütten ayrılmaya yönelik niyet ve arzusu" şeklinde tanımlanmaktadır (Bothma ve Roodt, 2013, s. 2). Araştırmalar, işten ayrılma niyeti ile işten ayrılma davranışı arasında güçlü bir ilişki olduğunu göstermektedir (Cho ve Lewis, 2012; Hancock, Bosco, McDaniel ve Pierce, 2013). Bu anlamda işten ayrılma niyeti, örgütlerde işgücü devir hızının yükselmesine neden olmakta, örgütsel etkinliği ve örgütsel başarıyı olumsuz etkilemektedir (Memon, Mohamed ve Baharom, 2016: 407).

Diğer taraftan çalışanların işten ayrılma niyeti üzerinde birçok faktör etkili olmaktadır. Yapılan araştırmalar iş tatmini, örgütsel bağlılık, iş aile çatışması (Çalışır, Gümüşsoy ve Işkın, 2011; Li, Sawhney ve Tortorella, 2019), algılanan örgütsel destek (Joo, Hahn ve Peterson, 2015), liderlik tarzı, örgüt kültürü, örgüt iklimi (Ak, 2018), iş stresi (Lo, Chien, Hwang, Huang ve Chiou, 2017) ve tükenmişlik (Aslan, 2014; Çalışkan ve Pekkan, 2019) gibi faktörlerin işten ayrılma niyeti üzerinde etkili olduğunu göstermektedir.

İşten ayrılma niyetine etki eden önemli faktörlerden biri de müşteriden kaynaklanan saldırgan davranışlardır. Araştırmalar, müşteri kaynaklı olumsuz davranışların çalışanın işi bırakma niyetinin kaynağı olabileceğini göstermektedir (Walsh, 2011, s. 68). Liu vd. (2018) tarafından yapılan çalışma, 
işyeri şiddetinin işten ayrılma niyetini pozitif etkilediğini göstermektedir. Gong vd. (2018) çalışmasında müşteri sözlü saldırganlığının işten ayrılma niyeti üzerinde pozitif bir etkiye sahip olduğunu tespit etmiştir. Bamfo vd. (2018) tarafından yapılan çalışmada da taciz edici müşteri davranışlarının işten ayrılma niyetini arttırdığı görülmektedir. Walsh (2011) tarafindan yapılan bir araştırma ise, hizmet sektörü çalışanlarının dostça olmayan müşteri algısının iş tatmini üzerinde dolaylı ve doğrudan bir etkiye sahip olduğunu ve bunun da işten ayrılma niyetini etkilediğini göstermektedir. Bu bilgiler 1şığında çalışmanın ikinci hipotezi şu şekilde belirlemiştir:

H2: Müşteri sözlü saldırganlığı çalışanların işten ayrılma niyetini pozitif etkilemektedir.

\section{Duygusal Tükenme ve İşten Ayrılma Niyeti}

Tükenmişliğin stres boyutunu temsil eden duygusal tükenme, çalışanların fiziksel ve duygusal aşınma yaşamasına neden olan etmen olarak değerlendirilmektedir (Ünlü ve Yürür, 2015, s. 186-187). Duygusal tükenme yaşayan çalışanlar, başka insanlara yardım edemeyeceğini ve onların sorunlarına çözüm üretemeyeceğini düşündüğü için kendini güçsüz ve yetersiz hissetmektedir (Faiz, 2019, s. 28). Ayrıca duygusal tükenme müşteri ile iletişim gerektiren işlerde daha yoğun olarak hissedilmektedir (Güğercin, 2019, s. 181). Bunun doğal bir sonucu olarak da çalışanın duygusal ve fiziksel olarak işinden ayrılmasının nedenlerinden biri olarak görülmektedir (Onay ve K1lc1, 2011, s. 372; Yıldırım, Erul, Kelebek, 2014, s. 40; Yıldız ve Çolak, 2018, s. 625; Faiz, 2019, s. 34; Adams, Hollingsworth, Osman, 2019, s. 455; Kim, 2019, s. 21). Bu bilgiler ışığında çalışmanın üçüncü hipotezi şu şekilde belirlenmiştir:

\section{H3: Duygusal tükenme işten ayrılma niyetini pozitif etkilemektedir.}

\section{Müşteri Sözlü Saldırganlığının İşten Ayrılma Niyeti Üzerine Etkisinde Duygusal Tükenmenin Aracılık Etkisi}

Araştırmalar, tükenmişliğin işten ayrılma niyeti üzerinde aracılık etkisine sahip olduğunu göstermektedir. Yücel ve Yücel (2018) tarafından hastane çalışanları üzerinde yapılan bir araştırmada iş tatmini ile işten ayrılma niyeti arasındaki ilişkide tükenmiş̧liğin aracılık etkisi olduğu tespit edilmiştir. Çetin, Güleç ve Kayasandık (2015) tarafından gerçekleştirilen çalışmada da etik iklim algısının işten ayrılma niyeti üzerindeki etkisinde tükenmişliğin aracılık etkisi olduğu görülmüştür. Han, Han, An ve Lim (2014) ise çalışmasında 
rol belirsizliği ve rol çatışmasının işten ayrılma niyeti üzerine etkisinde tükenmişliğin aracılık etkisi olduğunu tespit etmiştir.

Diğer taraftan müşteriden kaynaklanan saldırgan davranışların işten ayrılma niyeti üzerine etkisinde tükenmişliğin aracılık etkisini inceleyen çalışmalar da mevcuttur. Han vd. (2016) çalışmasında müşteri nezaketsizliğinin işten ayrılma niyeti üzerine etkisinde tükenmişliğin aracılık etkisine sahip olduğunu tespit etmiştir. Karatepe vd. (2009b) çalışmasında müşteri sözlü saldırganlığının işten ayrılma niyeti üzerine etkisinde duygusal tükenmenin aracılık etkisine sahip olduğunu göstermiştir. Grandey vd. (2004) çalışmasında müşteri sözlü saldırganlığı ile devamsızlık arasındaki ilişkide duygusal tükenmişliğin aracılık etkisine sahip olduğunu tespit etmiştir. $\mathrm{Bu}$ bilgiler 1şığında araştırmanın dördüncü hipotezi şu şekilde belirlenmiştir:

H4: Müşsteri sözlü saldırganlığının işten ayrllma niyeti üzerine etkisinde duygusal tükenmenin aracılık etkisi vardır.

\section{Yöntem}

Çalışmanın bu bölümünde, araştırmanın yöntemine, örneklemine, araştırmada kullanılan ölçüm araçlarına ve verilerin analizinde kullanılan yöntemlere ilişkin bilgilere verilmiştir.

\section{Araştırmanın Örneklemi}

Veri toplama tekniği olarak anket yönteminin kullanıldığı araştırmanın örneklemini, Trabzon ilinde hizmet sektöründe satış ve müşteri temsilcisi olarak çalışan 381 kişi oluşturmaktadır. Hazırlanan anket formu, Ortahisar ilçesindeki cadde ve alışveriş merkezi çalışanlarına Eylül 2019-Aralık 2019 tarihleri arasında uygulamıştır. Verilerin analizi aşamasına geçildiğinde 30 anketin eksik ya da hatalı olduğu tespit edilmiş ve bu anketler değerlendirme dışı bırakılmıştır. Böylece analizler 351 geçerli anket üzerinden gerçekleştirilmiştir.

Araştırmaya katılanların \%50,4'ü kadın, \%48,4'ü evli, \%39'u üniversite düzeyinde eğitime sahiptir. Katılımcıların yaşları 18 ile 50 arasında değişmekte olup yaş ortalaması $29( \pm 5,96)$, deneyimleri ise 1 ile 27 yıl arasında değişmekte olup ortalaması yaklaşık 6 yıl $( \pm 4,97)$ olarak hesaplanmıştır. 


\section{Araştırmada Kullanılan Ölçüm Aracı}

Araştırmada kullanılan veri toplama aracı dört bölümden oluşmaktadır. İlk bölüm katılımcıların demografik özelliklerini belirlemeyi amaçlamaktadır ve bu bölümde 5 soru bulunmaktadır (cinsiyet, medeni durum, eğitim durumu, yaş ve deneyim).

İkinci bölüm müşteri temsilcilerinin maruz kaldıkları müşteri sözlü saldırganlığını tespit etmeyi amaçlamaktadır. Bu bölümde kullanılan ölçek Dormann ve Zapf (2004) tarafından geliştirilmiş, yazarlar tarafından Türkçe geçerlik ve güvenirlik çalışması yapılmış olan müşterilerin neden olduğu sosyal stresörler ölçeğinin alt boyutu olan ve 5 maddeden oluşan müşteri sözlü saldırganlığı ölçeğidir (Örnek madde: Müşteriler sık sık bize bağırırlar).

Üçüncü bölüm müşteri temsilcilerinin yaşadıkları duygusal tükenme düzeyini tespit etmeyi amaçlamaktadır. $\mathrm{Bu}$ bölümde kullanılan ölçek Maslach ve Jackson (1981) tarafindan geliştirilmiş, Üngüren, Doğan, Özmen ve Tekin (2010) tarafından Türkçe geçerlik güvenirlik çalışması yapılmış olan tükenmişlik ölçeğinin alt boyutu olan ve 9 maddeden oluşan duygusal tükenme ölçeğidir (Örnek madde: İşimden soğuduğumu hissediyorum).

Son bölüm ise müşteri temsilcilerinin işten ayrılma niyetini tespit etmeyi amaçlamaktadır. Bu bölümde kullanılan ölçek Cammann, Fichman, Jenkins ve Klesh (1979) tarafindan geliştirilmiş, Gül, Gökçe ve Gökçe (2004) tarafından Türkçe geçerlik güvenirlik çalışması yapılmış olan ve 3 maddeden oluşan işten ayrılma niyeti ölçeğidir (Örnek madde: şimdiki işimden ayrılmayı düşünüyorum).

Tüm ölçeklerde yer alan maddeler "1: hiçbir zaman" ile "5: her zaman" arasında değişen beşli likert tipi değerlendirmeyle ölçülmüştür.

\section{Verilerin Analizi}

Araştırmada gerçekleştirilen analizlerin tümü SPSS 22 programı ile yapılmıştır. Öncelikle araştırmada kullanılan verilerin normal dağılım gösterip göstermediğini tespit etmek için Kolmogorov-Smirnov Testi uygulanmış ve gerçekleştirilen analiz sonrasında değişkenlerin normal dağılım ölçülerine uymadığı görülmüş, bu sebeple ileri sürülen hipotezlerin test edilmesi için analizlerde normal dağılım ön koşulu aramayan Preacher ve Hayes (2004: 721-722) tarafından geliştirilen SPSS eklentisi kullanılmıştır. Aracılık 
etkisinin tahmini için 5000 yeniden örnekleme (bootstrapping) ve \%95'lik güven aralığının belirlenmesi için ise yüzdelik hata düzeltilme tekniği (bias corrected percentile method) kullanılmıştır.

\section{Bulgular}

Araştırmanın bu bölümünde ilk olarak değişkenlere ilişkin bilgiler paylaşılmış ve ardından da hipotezlerin test sonuçlarına yer verilmiştir.

Tablo 1

Değişkenlere İlişkin Tanımlayıcı İstatistikler ve Güvenirlik Değerleri

\begin{tabular}{lccc}
\hline \multicolumn{1}{c}{ Değişkenler } & Madde Sayısı & Ortalama \pm SS & Cronbach's Alpha \\
\hline Müş̧teri Sözlü Saldırganlığı & 5 & $2,40( \pm 0,81)$ & 0,83 \\
Duygusal Tükenme & 9 & $2,82( \pm 0,96)$ & 0,93 \\
İşten Ayrılma Niyeti & 3 & $2,85( \pm 1,66)$ & 0,95 \\
\hline
\end{tabular}

Tablo 1, değişkenlere ilişkin tanımlayıcı istatistikleri ve güvenirlik değerlerini göstermektedir. Buna göre, katılımcıların müşteri sözlü saldırganlığı algısı ortalaması 2,40 ( $\pm 0,81)$, duygusal tükenme ortalaması 2,82 $( \pm 0,96)$ ve işten ayrılma niyeti ortalaması $2,85( \pm 1,66)$ olarak hesaplanmıştır. Ayrıca müşteri sözlü saldırganlık ölçeğinin içsel tutarlık oranı (Cronbach's Alpha) 0,83, duygusal tükenme ölçeğinin içsel tutarlık oranı 0,93 ve işten ayrılma niyeti ölçeğinin içsel tutarlık oranı 0,95 olarak hesaplanmıştır. Elde edilen bu değerler çalışmada kullanılan ölçeklerin içsel tutarlılık değerlerinin, sosyal bilimlerde kabul edilebilir sınırların üzerinde olduğunu göstermektedir.

Tablo 2

Aracılık Modeline İlişskin Sonuçlar

\begin{tabular}{|c|c|c|c|c|c|}
\hline & $\begin{array}{l}\text { Dolaylı etki } \\
\text { tahmini }\end{array}$ & $\begin{array}{c}\text { Dolaylı etki } \\
\text { tahminlerinin } \\
\text { ortalaması }\end{array}$ & $\begin{array}{c}\text { Standart } \\
\text { hata }\end{array}$ & $\begin{array}{c}\text { Alt } \% 95 \\
\text { güven } \\
\text { aralığı }\end{array}$ & $\begin{array}{c}\text { Üst } \% 95 \\
\text { güven } \\
\text { aralığı }\end{array}$ \\
\hline \multirow[t]{2}{*}{ Duygusal Tükenme } & 0,5744 & 0,5768 & 0,0855 & 0,4082 & 0,7448 \\
\hline & $F: 352,77$ & $p: 0,00$ & $\begin{array}{c}R 2: \\
\% 66,97\end{array}$ & $\begin{array}{c}\text { Sobel Z: } \\
6,6789\end{array}$ & $p: 0,00$ \\
\hline
\end{tabular}

Tablo 2, aracılık modeline ilişkin sonuçları göstermektedir. Buna göre kurulan model anlamlıdır (F: 352,77; p: 0,00) ve modelin açıklayıcılık gücü $\% 67$ seviyesindedir. Ayrıca kurulan aracılık modelindeki alt ve üst güven aralıkları sıfır değerini içermediği için (Karatuna ve Başol, 2017, s. 67; Serinikli, 2019, s. 591) aracılık etkisinin de anlamlı olduğu sonucuna (Alt: 0,40; Üst: 0,74) ulaşmak mümkündür (Sobel Z: 6,6789; p: 0,00). 


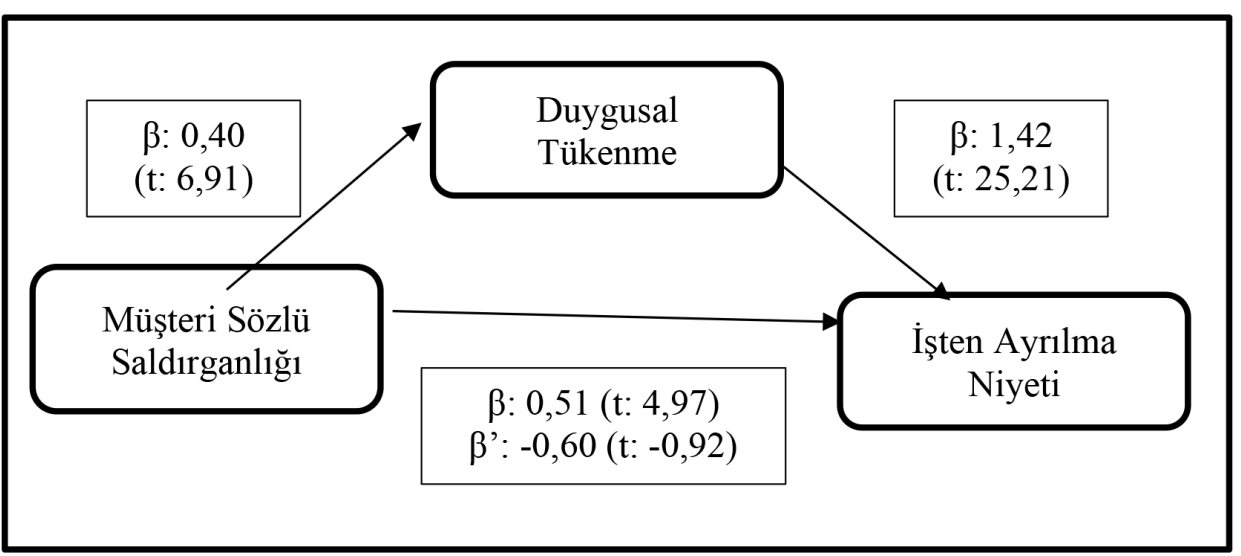

Şekil 1. Model Sonuçları

Şekil 1, elde edilen model sonuçlarını göstermektedir. Buna göre, müşteri sözlü saldırganlığının, duygusal tükenme üzerinde pozitif bir etkiye sahip olduğu $\left(\mathrm{H}_{1}\right)$ belirlenmiştir $(\beta$ : 0,40 ; t: 6,91). Elde edilen sonuçlara göre, çalışanların müşteri sözlü saldırganlığı algılarında meydana gelen bir birimlik artış, duygusal tükenme seviyesini 0,40 birim arttırmaktadır. Elde edilen bir diğer bulgu; müşteri sözlü saldırganlığının, çalışanların işten ayrılma niyetini $\left(\mathrm{H}_{2}\right)$ pozitif etkilediğidir ( $\beta$ : 0,$51 ; \mathrm{t}: 4,97)$. Buna göre, çalışanların müşteri sözlü saldırganlığı algılarında meydana gelen bir birimlik artış, işten ayrılma niyetini 0,51 birim arttırmaktadır. Analiz sonucunda elde edilen bir diğer bulgu ise duygusal tükenmenin işten ayrılma niyetini $\left(\mathrm{H}_{3}\right)$ pozitif etkilediğidir $(\beta: 1,42 ; \mathrm{t}: 25,21)$. Buna göre, çalışanların duygusal tükenme düzeyinde meydana gelen bir birimlik artış, işten ayrılma niyetini 1,42 birim arttırmaktadır. Şimdiye dek elde edilen sonuçlar incelendiğinde, müşteri sözlü saldırganlığının çalışanların duygusal tükenme ve işten ayrılma niyeti düzeylerini arttırdığını, duygusal tükenmenin de işten ayrılma niyeti üzerinde anlamlı bir etkiye sahip olduğunu söylemek yerinde olacaktır. Son olarak, müşteri sözlü saldırganlığının işten ayrılma niyeti üzerindeki etkisinde duygusal tükenmenin arac1lı etkisine sahip olduğu $\left(\mathrm{H}_{4}\right)$ tespit edilmiştir ( $\beta$ ': $-0,60$; t: $-0,92$ - Sobel Z: 6,6789; p: 0,00). Buna göre, çalışanların algıladığı müşteri sözlü saldırganlığında meydana gelen bir artış, çalışanların işten ayrılmasını doğrudan etkilememekte, bunun yerine müşteri sözlü saldırganlığında meydana gelen bir artış, çalışanların duygusal tükenme seviyesini arttırmakta, duygusal tükenme seviyesi artan çalışanın da işten ayrılma niyeti yükselmektedir. Diğer bir ifadeyle, müşteri sözlü saldırganlığı ile işten ayrılma niyeti arasında duygusal tükenmenin tam aracı rolü vardır. 


\section{Sonuç ve Tartışma}

Müşteri saldırganlığı olgusu, hizmet sektöründe çalışanların günümüzde karşılaştığ1 önemli sorun alanlarından biridir. Mevcut araştırma, müşteri sözlü saldırganlığı ile çalışanların işten ayrılma niyeti ilişkisinde duygusal tükenmenin aracılık rolünü belirlemeyi amaçlamaktadır. Satış ve müşteri temsilcilerinin katılımıyla yapılan bu araştırma sonucunda, müşteri saldırganlığının duygusal tükenme ve işten ayrılma niyeti üzerinde pozitif bir etkiye sahip olduğu tespit edilmiştir. Bu sonuçlara göre araştırmada ileri sürülen $H 1$ ve $H 2$ hipotezleri kabul edilmiştir. Literatürde yapılan bir çok araştırma da müşteri sözlü saldırganlığının yol açmış olduğu önemli sorunlardan birinin duygusal tükenme olduğunu göstermektedir (Ben-Zur ve Yagil, 2005; Grandey vd., 2007; Karatepe vd., 2010b; Dursun ve Aytaç, 2014; Sommovigo vd., 2019). Ayrıca müşteri saldırganlığı ile ilgili literatürde yapılan araştırmalar, müşteriden kaynaklanan bu tür olumsuz davranışların çalışanların işten ayrılma niyeti üzerinde de önemli bir etkiye sahip olduğunu göstermektedir (Karatepe vd., 2009a; Gong vd., 2018; Bamfo vd., 2018).

Ayrıca elde edilen sonuçlar, duygusal tükenmenin işten ayrılma niyeti üzerinde pozitif bir etkiye sahip olduğunu ve müşteri sözlü saldırganlığının işten ayrılma niyeti üzerindeki etkisinde duygusal tükenmenin aracılık rolü bulunduğunu göstermiştir (Sobel Z: 6,6789; p: 0,00). Bu sonuçlara göre araştırmanın H3 ve $H 4$ hipotezleri kabul edilmiştir. Elde edilen bu sonuçlar duygusal tükenmenin işten ayrılma niyeti üzerinde pozitif bir etkiye sahip olduğunu ve müşteri sözlü saldırganlığının işten ayrılma niyeti üzerindeki etkisinde duygusal tükenmenin aracılık rolü bulunduğunu gösteren diğer araştırma sonuçlarıyla uyumludur (Grandey vd., 2004; Karatepe vd., 2009; Onay ve K1lc1, 2011; Y1ldırım vd., 2014; Yıldız ve Çolak, 2018; Faiz, 2019; Adams vd., 2019; Kim, 2019).

Diğer taraftan, elde edilen sonuçlar işletme yönetimlerinin müşteriden kaynaklanan saldırgan davranışları önleyici politikalar üretmesinin, çalışanların duygusal tükenme ve işten ayrılma niyetinin azaltılması açısından oldukça önemli olduğunu göstermektedir. İşletme yönetimlerinin bu konuda gerekli önlemleri almadıkları takdirde çalışanlar işlerini bırakabilecekler ve bu durum işletmelerin işgücü devir hızını yükseltebilecektir. Nitekim, hizmet sektöründe işgücü devir hızının yüksekliği işletmelerin etkinliğini, verimliliğini ve üretkenliğini olumsuz etkilemekte (Yılmaz ve Halıcı, 2010; Alparslan ve Orhan, 2016) ve önemli maliyetlere yol açmaktadır. 
Ayrıca araştırmalar, müşteri saldırganlığının çalışanlar ve işletmeler üzerindeki olumsuz etkilerinin yalnızca bunlarla da sınırlı olmadığını göstermektedir. Örneğin Rafaeli vd. (2012) çalışmasında müşteri sözlü saldırganlığınınçalışanlarınbilişselvegörevperformansınılumsuzetkilediğini tespit etmiştir. Bir diğer araştırmada ise, müşteri sözlü saldırganlığının hizmet sabotaj davranışlarına yol açtı̆̆ görülmektedir (Yeh, 2015). Kim vd. (2012) ve Yoo vd. (2015) tarafindan gerçekleştirilen araştırmalarda müşteri sözlü saldırganlığının hizmet iyileştirme performansı üzerinde olumsuz etkiye sahip olduğu tespit edilmiştir. Dupr'e, Dawe ve Barling (2014) tarafından yürütülen çalışmada müşteri kaynaklı saldırganlığın duygusal bağlılığın azalmasına, mental ve fiziksel sağlığın olumsuz etkilenmesine neden olduğu görülmüştür. $\mathrm{Bu}$ sonuçlardan da anlaşılacağı üzere, müşteriden kaynaklanan saldırgan davranışların önlenmesi, çalışanın mevcut performansının arttırılması, hizmet kalitesinin yükseltilmesi, çalışanın fiziksel ve mental sağlığının korunması açısından oldukça önemlidir.

Müşteri saldırganlığının gerek çalışanlar gerekse de işletmeler açısından olumsuz etkileri dikkate alındığında, hizmet yöneticilerinin çalışanmüşteri etkileşimlerini daha etkili bir şekilde yönetmesi gerektiği sonucuna ulaşılmaktadır. Bu bağlamda yöneticiler, zor müşterilerle başa çıkmak için gerekli olan becerileri geliştirmek adına çalışanlarına eğitim verebilir veya hizmet sunma süreçlerinde bazı iyileştirmeler yapabilirler (Walsh, 2011). Ayrıca işletmeler, müşteriden kaynaklanan saldırgan davranışları önleyecek politikalar oluşturmalıdır. İşletmeler tarafından yapılacak düzenlemeler, çalışanların kurumlarına yönelik şiddet önleme algılarını etkileyecektir. Araştırmalar, şiddet önleme algısının çalışanların gelecekte şiddete uğrama ile ilgili korku düzeylerini ve işten ayrılma niyetlerini azalttığını göstermektedir (Mueller ve Tschan, 2011). Bu nedenle şiddet önlemeye yönelik olumlu bir örgütsel iklimin oluşturulması işletmeler açısından oldukça önemlidir.

\footnotetext{
Hakem Değerlendirmesi: Dış bağımsız.

Çıkar Çatışması: Yazarlar çıkar çatışması bildirmemiştir.

Finansal Destek: Yazarlar bu çalışma için finansal destek almadığını beyan etmiştir.

Peer-review: Externally peer-reviewed.

Conflict of Interest: The authors has no conflict of interest to declare.

Grant Support: The authors declared that this study has received no financial support.
} 


\section{Kaynakça/References}

Adams, A., Hollingsworth, A., \& Osman, A. (2019). The 1mplementation of a cultural change toolkit to reduce nursing burnout and mitigate nurse turnover in the emergency department. Journal of Emergency Nursing, 45(4), 452-456.

Ak, B. (2018). Turnover intention influencing factors of employees: An empirical work review. Journal of Entrepreneurship \& Organization Management, 7(3), 1-7.

Akgeyik, T. ve Delen, G. M. (2009). Müşteri saldırganlığg: Yaygınlığı ve aktörleri: (Bir Alan Araştırması). TISK Akademi, 8, 106-143.

Alparslan, E. ve Orhan, K. (2016). İşgücü kaybının nedenleri, etkileri ve alınabilecek önlemler: Denizli kablo ve tel üreticisi bir firmada araştırma. Çalışma İlişkileri Dergisi, $7(2), 41-64$.

Aslan, Z. (2014), İşgörenlerin tükenmişlik düzeylerinin işten ayrılma niyeti üzerine etkisi: İstanbul'daki seyahat acentalarında bir araştırma. Nevşehir Hacı Bektaş Veli Üniversitesi Sosyal Bilimler Enstitüsü Dergisi, 3, 19-40.

Bamfo, B. A. B., Dogbe, C. S. K., \& Mingle, H. (2018). Abusive customer behaviour and frontline employee turnover intentions in the banking industry: the mediating role of employee satisfaction. Cogent Business \& Management, 5(1), 1-15.

Baron, S. A. (1993). Violence in the workplace: A prevention and management guide for business. Ventura, CA: Pathfinder Publishing.

Bedi, A., \& Schat, A. C. H. (2007). Customer aggression: A theoretical and meta analytic review. The Meeting of Annual Conference of the Administrative Sciences Association of Canada, 21, 324-341.

Ben-Zur, H., \& Yagil, D. (2005). The relationship between empowerment, aggressive behaviours of customers, Coping, and Burnout. European Journal of Work and Organizational Psychology, 14(1), 81-99.

Boles, J. S., Dean, D. H., Ricks, J. M., Short, J. C., \& Wang, G. (2000). The dimensionality of the maslach burnout inventory across small business owners and educators. Journal of Vocational Behavior, 56(1), 12-34.

Bothma, C. F. C., \& Roodt, G. (2013). The validation of the turnover intention scale. SA Journal of Human Resource Management, 11(1), 1-12.

Cammann, C., Fichman, M., Jenkins, D., \& Klesh, J. (1979). The Michigan Organizational Assessment Questionnaire. University of Michigan Ann Arbor, Unpublished Manuscript.

Cho, Y. J., \& Lewis, G. B. (2012). Turnover intention and turnover behavior: Implications for retaining federal employees. Review of Public Personnel Administration, 32(1), 4-23.

Choi, C. H., Kim, T. T., Lee, G., \& Lee, S. K. (2014). Testing the stressor-strain-outcome model of customer-related social stressors in predicting emotional exhaustion, customer orientation and service recovery performance. International Journal of Hospitality Management, 36, 272-285. 
Çalışır, F., Gumussoy, C., \& Iskin, I. (2011). Factors affecting intention to quit among IT professionals in Turkey. Personnel Review, 40(4), 514-533.

Çalışkan, A. ve Pekkan, N. Ü (2019). Sağlık sektörü çalışanlarında tükenmişlik duygusunun işten ayrılma niyetine etkisi: Kişi - örgüt uyumunun aracılık rolü. Business and Economics Research Journal, 10(2), 469-481.

Çetin, A., Güleç, R. ve Kayasandık, A. E. (2015). Etik iklim algısının çalışanların işten ayrılma niyetine etkisi: Tükenmişliğin aracı değişken rolü. Electronic Journal of Vocational Colleges, 5(2), 18-31.

Dallimore, K. S., Sparks, B. A., \& Butcher, K. (2007). The influence of angry customer outbursts on service providers' facial displays and affective states. Journal of Service Research, 10(1), 78-92.

Demerdash, J. M., \& Said, H. M. (2018). The effect of customer verbal aggression on burnout in frontline employees in hotels and travel agencies: the moderating role of perceived supervisor support. Journal of Tourism and Hospitality Management, 6(6), 291-303.

Dormann, C., \& Zapf, D. (2004). Customer-related social stressors and burnout. Journal of Occupational Health Psychology, 9(1), 61-82.

Dupr'e, K. E., Dawe, K. A., \& Barling, J. (2014). Harm to those who serve: Effects of direct and vicarious customer-1nitiated workplace aggression. Journal of Interpersonal Violence, 29(13), 2355-2377.

Dursun, S., \& Aytaç, S. (2014). The effect of customer aggression on burnout. Academic Journal of Interdisciplinary Studies, 3(4), 369-372.

Faiz, E. (2019). Aşırı İş yükü ve tükenmişlik sendromunun işten ayrılma niyeti üzerindeki etkisi: satış personelleri üzerinde bir araştırma. Çalışma İlişkileri Dergisi, 10(1), 2638.

Fullerton, R., \& Punj. G. (1993). Choosing to misbehave: A structural model of aberrant consumer behavior. Advances in Consumer Research, 20, 570-574.

Getnet, H. T., \& Malik, M. D. R. (2012). Molding the Behavior of Aggressive Customers. http://www.diva-portal.org/smash/get/diva2:553348/FULLTEXT02.

Gong, Z., Sun, Y., \& Zhang, Z. (2018). The influence of customer's verbal abuse on turnover intention and job burnout of sales service staff-the moderating effect of organizational atmosphere and psychological capital. Psychology, 9, 2369-2383.

Goussinsky, R. (2011). Coping with customer aggression. Journal of Service Management, 23(2), 170-196.

Grandey, A. A., Dickter, D. N., \& Sin, H. (2004). The customer is not always right: Customer aggression and emotion regulation of service employees. Journal of Organizational Behavior, 25, 397-418.

Grandey, A., Kern, J., \& Frone, M. (2007). Verbal abuse from outsiders versus insiders: Comparing frequency, impact on emotional exhaustion, and the role of emotional labor. Journal of Occupational Health Psychology, 12, 63-79. 
Güğerçin, U. (2019). Duygusal emeğin duygusal tükenme üzerindeki etkisi: Özbenlik çelişki teorisi çerçevesinde bir analiz. Karadeniz Sosyal Bilimler Dergisi, 11(20), 177-192.

Gül, H., Gökçe, O. E. ve Gökçe, H. (2008). İş tatmini, iş stresi, örgütsel bağl1lık, işten ayrılma niyeti ve performans arasındaki ilişkiler: Sağlık sektöründe bir uygulama. Akademik Bakış, 15, 1-11.

Han, S. S., Han, J. W., An, Y. S., \& Lim, S. H. (2014). Effects of role stress on nurses' turnover intentions: the mediating effects of organizational commitment and burnout. Japan Journal of Nursing Science, 12, 287-296.

Han, S. J., Bonn, M. K., \& Cho, M. (2016). The relationship between customer incivility, restaurant frontline service employee burnout and turnover intention. International Journal of Hospitality Management, 52, 97-106.

Hancock, J. I., Bosco, F. A., McDaniel, K. R., \& Pierce, C. A. (2013). Meta-analytic review of employee turnover as a predictor of firm performance. Journal of Management, 39(3), 573-603.

Harris, L. C., \& Reynolds, K. L. (2003). The consequences of dysfunctional customer behavior. Journal of Service Research, 6(2), 144-161.

Hughes, K. D., \& Tadic, V. (1998). Something to deal with: Customer sexual harrassment and women's retail service work in Canada. Gender, Work, and Organization, 5(4), 207-219.

Joo, B. K., Hahn, H. J., \& Peterson, S. L. (2015). Turnover intention: the effects of core selfevaluations, proactive personality, perceived organizational support, developmental feedback, and job complexity. Human Resource Development International, 18(2), 116-130.

Karatepe, O. M., Yorganci, I., \& Haktanir, M. (2009). An investigation of the role of job resources in mitigating customer-related social stressors and emotional exhaustion. Services Marketing Quarterly, 31(1), 72-88.

Karatepe, O.M., Yorganci, I., \& Haktanir, M. (2009). Outcomes of customer verbal aggression among hotel employees. International Journal of Contemporary Hospitality Management, 21(6), 713-733.

Karatuna, I., \& Basol, O. (2017). Job satisfaction of part-time vs. full-time workers in Turkey: the effect of income and work status satisfaction. International Journal of Value Chain Management, 8(1), 58-72.

Kavi, E. ve Ceylan, Ş. (2016). Çalışanlara yönelik müşteri saldırganlığı ve Yalova ilindeki kargo çalışanlarına yönelik bir araştırma. HAK-IŞ Uluslararası Emek ve Toplum Dergisi, 5(13), 102-125.

Kim, T., Paek, S., Choi, C., \& Lee, G. (2012). Frontline service employees' customerrelated social stressors, emotional exhaustion, and service recovery performance: Customer orientation as a moderator. Service Business, 6(4), 503-526.

Kim, Y. (2019). Music therapists' job demands, job autonomy, social support, and their relationship with burnout and turnover intention. The Arts in Psychotherapy, 51, 17-23, 
Kind, N., Eckert, A., Steinlin, C., Ferget, J.M., \& Schmid, M. (2008). Verbal and physical client aggression-a longitudinal analysis of professional caregivers' psychophysiological stress response and burnout. Psychoneuroendocrinology, 94, 11-16.

Li, X., \& Zhou, E. (2013). Influence of customer verbal aggression on employee turnover intention. Management Decision, 51(4), 890-912.

Li, Y., Sawhney, R., \& Tortorella, G. L. (2019). Empirical analysis of factors impacting turnover intention among manufacturing workers. International Journal of Business and Management, 14(4), 1-18.

Liu, W., Zhao, S., Shi, L., Zhang, Z., Liu, X., Li, L., \& Ni, X. (2018). Workplace violence, job satisfaction, burnout, perceived organisational support and their effects on turnover intention among Chinese nurses in tertiary hospitals: A cross-sectional study. BMJ Open, 8(6), e019525. doi:10.1136/bmjopen-2017-019525.

Lizano, E. L. (2015). Examining the impact of job burnout on the health and wellbeing of human service workers: A systematic review and synthesis. Human Service Organizations Management, Leadership \& Governance, 39(3), 167-181.

Lo, W. Y., Chien, L. Y., Hwang, F. M. Huang, N., \& Chiou, S. T. (2017). From job stress to intention to leave among hospital nurses: A structural equation modelling approach. Journal of Advanced Nursing, 74, 677-688.

Maslach, C., \& Jackson, S. E. (1981). The measurement of experienced burnout. Journal of Organizational Behavior, 2(2), 99-113.

Memon, M. A., Mohamed, R. S., \& Baharom, N. R. (2016). The link between training satisfaction, work engangement and turnover intention. European Journal of Training and Development, 40(6), 407-426.

Molino, M., Emanuel, F., Zito, M., Ghislieri, C., Colombo, L., \& Cortese, C. (2016). Inbound call centers and emotional dissonance in the job demands-resources model. Front Psychology, 7, 1-12.

Mueller, S., \& Tschan, F. (2011). Consequences of client-1nitiated workplace violence: the role of fear and perceived prevention. Journal of Occupational Health Psychology, 16(2), 217-229.

Onay, M. ve Kılcı, S. (2011). İş stresi ve tükenmişlik duygusunun işten ayrılma niyeti üzerine etkileri: Garsonlar ve aşçıbaş1lar. Organizasyon ve Yönetim Bilimleri Dergisi, 3(2), 363-372.

Patterson, P. G., McColl-Kennedy, J. R., Smith, A. K., \& Lu, Z. (2009). Customer rage: Triggers, tipping points, and takeouts. California Management Review, 52(1), 6-28.

Preacher, K. J., \& Hayes, A. F. (2004). SPSS and SAS procedures for estimating 1ndirect effects in simple mediation models. Behavior Research Methods, 36(4), 717-731.

Rafaeli, A., Erez, A., Ravid, S., Derfler-Rozin, R., Treister, D. E., \& Scheyer, R. (2012). When customers exhibit verbal aggression, employees pay cognitive costs. Journal of Applied Psychology, 97(5), 931-950. 
Reynolds, K. L., \& Harris, L. C. (2006). Deviant customer behavior: An exploration of frontline employee tactics. Journal of Marketing Theory and Practice, 14(2), 95-111.

Rupp, D. E., McCance, A. S., Spencer, S., \& Sonntag, K. (2008). Customer (In)Justice and emotional labor: the role of perspective taking, anger, and emotional regulation. Journal of Management, 34(5), 903-924.

Serinikli, N. (2019). Çalışanların örgütsel destek algılarının iş tatminlerine etkisinde iş stresinin arac1lık rolü. Gümüşhane Üniversitesi Sosyal Bilimler Enstitüsü Elektronik Dergisi, 10(3), 585-597.

Singh, J., Goolsby, J. R., \& Rhoades, G. K. (1994). Behavioral and psychological consequences of boundary spanning burnout for customer service representatives. Journal of Marketing Research, 16, 558-569.

Sommovigo, V., Setti, I., \& Argentero, P. (2019). The role of service providers' resilience in buffering the negative impact of customer incivility on service recovery performance. Sustainability, 11(1), 1-22.

Tett, R. P., \& Meyer, J. P. (1993). Job satisfaction, organizational commitment, turnover intention, and turnover: Path analyses based on metaanalytic findings. Personnel Psychology, 46, 259-293.

Üngüren, E., Doğan, H., Özmen, M. ve Tekin, Ö. A. (2010). Otel çalışanlarının tükenmiş̧lik ve iş tatmin düzeyleri ilişkisi. Journal of Yaşar University, 17(5), 2922-2937.

Ünlü, O. ve Yürür, S. (2015). Duygusal emek, duygusal tükenme ve görev/bağlamsal performans ilişkisi: Yalova'da hizmet sektörü çalışanları ile bir araştırma. Erciyes Üniversitesi İktisadi ve İdari Bilimler Fakültesi Dergisi, 37, 183-207.

Walsh, G. (2011). Unfriendly customers as a social stressor - anindirect antecedent of service employees' quitting intention. European Management Journal, 29(1), 67-78.

Wang, M., Liao, H., Kammeyer-Mueller, J., Liu, S., Gong, Y., \& Shi, J. (2013). Can't get it out of my mind: Employee rumination after customer mistreatment and negative mood in the next morning. Journal of Applied Psychology, 98(6), 989-1004.

Yeh, C. W. (2015). Linking customer verbal aggression and service sabotage. Journal of Service Theory and Practice, 25(6), 877-896.

Yıldırım, M., Erul, E. ve Kelebek, P. (2014). Tükenmişlik ile işten ayrılma niyeti arasındaki ilişki banka çalışanları üzerine bir araştırma. Organizasyon ve Yönetim Bilimleri Dergisi, 6(1), 34-44.

Yıldız, S. ve Çolak, U. (2018). Liderlik davranış tarzlarının örgütsel tükenmişlik ve işten ayrılma eğilimlerine etkileri: Seyahat acentaları üzerine bir araştırma. MANAS Sosyal Araştırmalar Dergisi, 7(4), 607-632.

Yılmaz, B. ve Halıcı, A. (2010). İşgücü devir hızını etkileyen etmenler: sekreterlik mesleğinde bir araştırma. International Journal of Economic and Administrative Studies, 2(4), 93-108.

Yoo, J., Kim, T., \& Lee, G. (2015). When customers complain: the value of customer orientation in service recovery. Cornell Hospitality Quarterly, 56(4), 411-426. 
Yücel, İ. ve Yücel, D. (2018). İş tatmini ve işten ayrılma niyeti arasındaki ilişkide tükenmişliğin aracılık etkisi: Sağlı sektöründe bir çalışma. MANAS Sosyal Araştırmalar Dergisi, 7(2), 297-321.

Yürür, Ş., Gümüş, M. ve Hamarat, Ş. (2011). Çalışan-müşteri ilişkilerinde algılanan adalet/adaletsizliğin duygusal emek davranışlarına etkisi. Journal of Yaşar University, 6(23), 3826-3839. 
